\title{
Nutritional Keys for Intestinal Barrier Modulation
}

\author{
Stefania De Santis ${ }^{1}$, Elisabetta Cavalcanti ${ }^{1}$, Mauro Mastronardi ${ }^{2}$, Emilio Jirillo ${ }^{3}$ and \\ Marcello Chieppa ${ }^{1,4 *}$
}

'Laboratory of Experimental Immunopathology, IRCCS "De Bellis", Castellana Grotte, Italy, ${ }^{2}$ Department of Gastroenterology, IRCCS "De Bellis", Castellana Grotte, Italy, ${ }^{3}$ Department of Basic Medical Sciences, Neuroscience and Sensory Organs, University of Bari, Bari, Italy, ${ }^{4}$ stituto Comprensivo Bregante-Volta, Monopoli, Italy

\section{OPEN ACCESS}

Edited by:

Lorraine M. Sordillo,

Michigan State University, USA

Reviewed by:

Matteo A. Russo,

Sapienza University of Rome, Italy

Douglas W. Bigwood,

DBE Technologies, USA

${ }^{*}$ Correspondence:

Marcello Chieppa

transmed@irccsdebellis.it

Specialty section:

This article was submitted to

Nutritional Immunology,

a section of the journal

Frontiers in Immunology

Received: 28 September 2015

Accepted: 22 November 2015

Published: 07 December 2015

Citation:

De Santis S, Cavalcanti E.

Mastronardi M, Jirillo $E$ and

Chieppa M (2015) Nutritional Keys for

Intestinal Barrier Modulation.

Front. Immunol. 6:612.

doi: 10.3389/fimmu.2015.00612
The intestinal tract represents the largest interface between the external environment and the human body. Nutrient uptake mostly happens in the intestinal tract, where the epithelial surface is constantly exposed to dietary antigens. Since inflammatory response toward these antigens may be deleterious for the host, a plethora of protective mechanisms take place to avoid or attenuate local damage. For instance, the intestinal barrier is able to elicit a dynamic response that either promotes or impairs luminal antigens adhesion and crossing. Regulation of intestinal barrier is crucial to control intestinal permeability whose increase is associated with chronic inflammatory conditions. The cross talk among bacteria, immune, and dietary factors is able to modulate the mucosal barrier function, as well as the intestinal permeability. Several nutritional products have recently been proposed as regulators of the epithelial barrier, even if their effects are in part contradictory. At the same time, the metabolic function of the microbiota generates new products with different effects based on the dietary content. Besides conventional treatments, novel therapies based on complementary nutrients are now growing. Fecal therapy has been recently used for the clinical treatment of refractory Clostridium difficile infection instead of the classical antibiotic therapy. In the present review, we will outline the epithelial response to nutritional components derived from dietary intake and microbial fermentation focusing on the consequent effects on the integrity of the epithelial barrier.

Keywords: inflammation, intestinal permeability, nutrition, mucosal immunity, microbiota

\section{INTRODUCTION}

The intestinal tract is the largest interface between the body and the external environment represented by the intestinal lumen (1). The structure of the intestinal wall consists of a mucosa that is highly specialized in each part of the intestinal tract. In the small and large intestine, the mucosa consists of a single monolayer of epithelial cells critical to both absorb nutrients and avoid the entry of potentially harmful entities, including microorganisms or dietary antigens (2). To concomitantly fulfill both functions, the intestinal barrier permeability is regulated by a dynamic process. The entry of small amounts of nutritional antigens and microorganisms can occur even without a pathogenic response. This event induces a homeostatic immune response characterized by immune tolerance to these antigens (3). Intestinal barrier damage can be primarily due to an enhancement of the paracellular permeability associated with an increased permeation of luminal antigens. These events in turn cause the activation of the mucosal immunity finally leading to sustained inflammation and tissue 
damage (4). Intestinal permeability is a dynamic process whose regulation is determined by the interaction among several players, including barrier constituents, immune cells, microbiota, and also external factors, such as the diet. Alterations of mucosal barrier function are increasingly linked to a broad spectrum of pathologies (5-7), including intestinal disorders such as inflammatory bowel disease (IBD) (8). For this reason, a deeper understanding of the multiple mechanisms involved in the regulation of the mucosal barrier is needed. The main focus of this review is to summarize how nutrition can influence the intestinal barrier function.

\section{THE INTESTINAL BARRIER}

The intestinal barrier is an heterogeneous entity that is composed of cellular and extracellular components (9). The cellular part is defined by the intestinal epithelium and the underlying lamina propria. The intestinal epithelium contains five distinct types of cells: stem cells with interposed Paneth cells producing antimicrobial peptides (AMPs), absorptive enterocytes, mucus secreting goblet cells, and hormone producing enteroendocrine cells (10). Lamina propria contains dendritic cells (DCs), intraepithelial DCs (IEDCs), macrophages, intraepithelial lymphocytes (IEL), T regulatory cells (T Regs), TCD4+ lymphocytes, B lymphocytes, and plasma cells $(11,12)$. The extracellular component of the barrier is represented by the mucus layer secreted by goblet cells. The mucus is crucial to facilitate food passage, to protect the epithelial cells from the action of digestive enzymes present in the lumen, and to avoid the firm adhesion of bacteria to the epithelial cells, thus preventing their entry into the lamina propria (13). This function is implemented by AMPs and secretory (s) IgA dimers released by plasma cells (14) (Figure 1).

The intestinal barrier integrity is essential for the intestinal permeability; specifically, intestinal epithelial cells (IECs) have a major role in this context $(15,16)$. The epithelial monolayer represents a physical barrier due to the fact that in the absence of specific transporters the plasma membrane of these cells is impermeable to the majority of hydrophilic solutes (9). Epithelial cells are held together by the apical junctional complexes, consisting of adherent junctions and tight junctions (TJs), as well as by underlying desmosomes (17). Adherent junctions and desmosomes are a site of intercellular communication that close together adjacent IECs providing strong bonds between them without altering paracellular permeability as in the case of TJs. TJs are composed of four transmembrane (TM) proteins: such as claudins (18), occludin (19), junctional adhesion molecules (JAMs) (20), and tricellulin (21), and some cytosolic scaffold proteins, such as zonulae occludens (ZO) and cingulin $(22,23)$. The extracellular domains of the TM proteins form a selective barrier through both homophilic and heterophilic interactions with nearby cells. Conversely, the intracellular domains of TM proteins are linked to the perijunctional actomyosin ring by the interaction with cytosolic

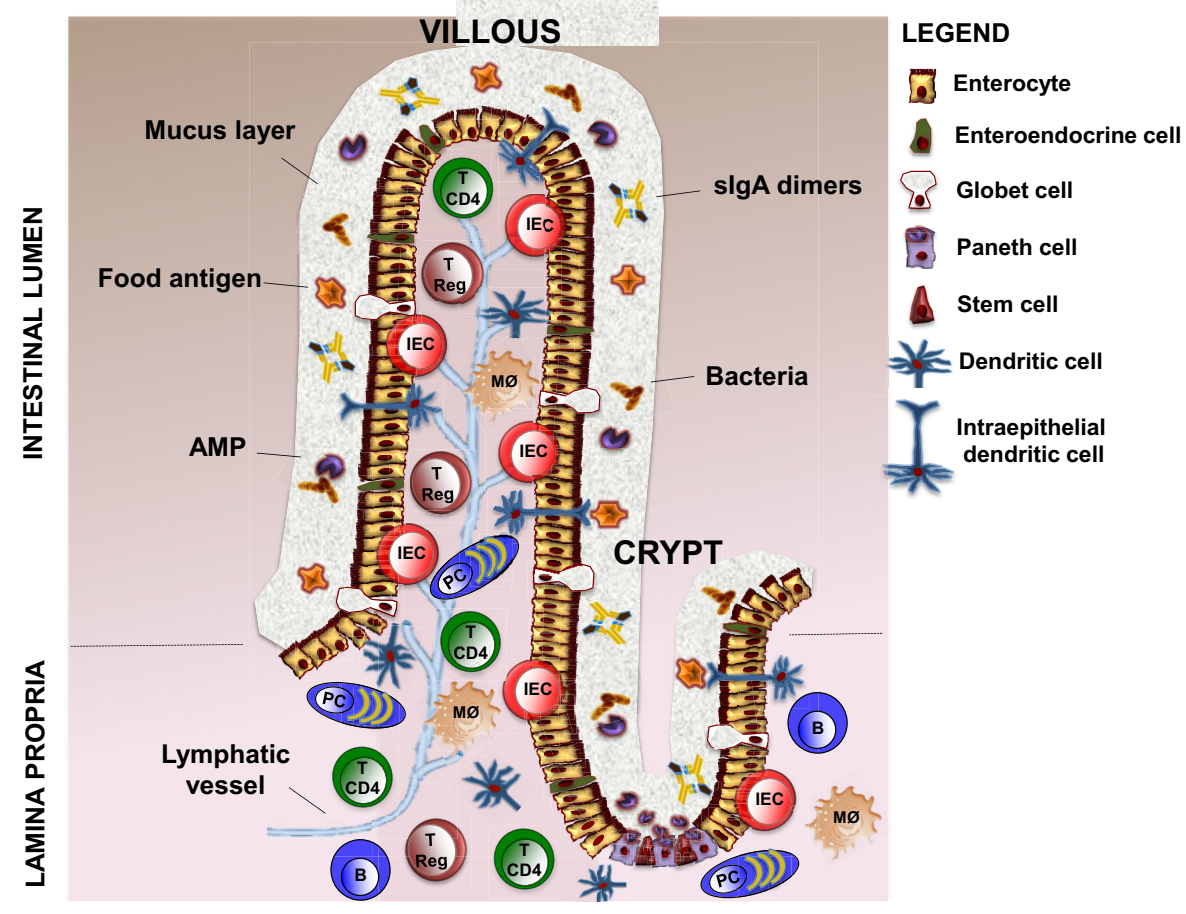

FIGURE 1 | Structure of intestinal barrier. The intestinal barrier is a complex entity, which is composed of cellular and extracellular elements. The cellular part is defined by intestinal epithelium (five distinct type of cells, such as stem cells, Paneth cells, enterocytes, goblet cells, and enteroendocrine cells) and the underlying lamina propria, which contains DCs (also intraepithelial DCs, IEDCs), macrophages, intraepithelial lymphocytes (IEL), T regulatory cells (T Regs), TCD4+ lymphocytes ( $\mathrm{T} \mathrm{CD4),} \mathrm{B} \mathrm{lymphocytes} \mathrm{(B),} \mathrm{and} \mathrm{plasma} \mathrm{cells} \mathrm{(PCs).} \mathrm{The} \mathrm{extracellular} \mathrm{component} \mathrm{consists} \mathrm{in} \mathrm{a} \mathrm{mucus} \mathrm{layer} \mathrm{produced} \mathrm{by} \mathrm{Globet} \mathrm{cells,} \mathrm{AMPs} \mathrm{secreted} \mathrm{by} \mathrm{Paneth}$ cells, and slgA dimers released by plasma cells. DCs, dendritic cells; AMPs, antimicrobial peptides; slgA, secretory ImmunoglobulinA. 
scaffold proteins (24). This interaction permits the cytoskeletal regulation of TJ-mediated barrier integrity (17). TJs are also important in determining the charge selectivity of the paracellular pathway (25). Specifically, this effect is exerts by claudins (26). In fact, in the intestine, claudin-2 forms cation-selective channels in TJs (27). TJs are highly regulated at transcriptional and post-transcriptional levels by physiological or pathophysiological stimuli (9); among these, an important role has been attributed to nutrients, as discussed below.

\section{INTESTINAL PERMEABILITY AND TRANSPORT PATHWAYS}

Intestinal permeability is an intrinsic property of the intestine that is defined as "the facility with which intestinal epithelium allows molecules to pass through by non-mediated passive diffusion" (28). The transport of molecules from the intestinal lumen to the lamina propria can occur through two different pathways: the paracellular diffusion of small molecules by TJs and the transcellular transport through transcytosis (endocytosis/exocytosis) of large molecules mediated or not by membrane receptors (29). Both pathways allow luminal antigens to gain access to the subepithelial compartment and to interact with local immune cells.

Paracellular permeability is mainly determined by pore size in TJs, determining a high-capacity pathway that is size-restricted and a low-capacity pathway, independent of size. The latter can be due to transient (e.g., apoptosis) or fixed breaks (different TJ proteins) in the epithelial cells (29). In fact, small and large pores are defined by different TJ proteins, such as claudins (30, 31) and tricellulin (17), respectively. The paracellular diffusion of small molecules through TJ pores is driven by water movement in response to electrochemical or osmotic gradients across the epithelium (29).

Transcellular transport pathways can be mediated by different type of cells; M cells overlying Payer's patches (PPs) and isolated lymphoid follicles (32), DCs (33-35), goblet cells (36), and columnar enterocytes. Enterocytes sample molecules of high molecular weight, such as food antigens, by endocytosis at the apical membrane and transcytosis toward the lamina propria $(37,38)$. During transcytosis, full-length proteins are degraded in acidic and lysosomal compartments of enterocytes and released at the basolateral membrane as amino acids when totally degraded or as immunogenic peptides if partially degraded (39). Immunogenic peptides released into the lamina propria can be taken up by local antigen-presenting cells (APCs) and activate the immune response (40); alternatively, they can be transported into the draining lymph nodes by lacteals (41). The presence of food antigens in the form of small immunogenic peptides suggests that during transcytosis, a mechanism that avoids their total degradation might occur (42). This could be due to exosome-like structures produced by IECs. Exosomes are small membrane vesicles $(\sim 80 \mathrm{~nm}$ in diameter) resulting from inward membrane invagination of the MHC class II-enriched compartments in which luminal antigens arrived after endosomal degradation (43). These compartments can both lead to lysosomes or fuse with the plasma membrane. Exosomes released outside the cells interact with local immune cells (44). Exosome-bound peptides are more efficient in interacting with DCs and promoting antigen presentation to T cells than free peptides (45). Also, in humans, it was demonstrated that HLA-DR/peptide complexes bound to exosome-like vesicles were highly immunogenic (46).

The transcytosis of food antigens occurs primarily by a fluid-phase endocytosis of proteins at the apical membrane of enterocytes (29). However, the access of luminal antigens into the intestinal mucosa is also possible thanks to the expression of immunoglobulin receptors (IgR) expressed on the apical surface of enterocytes (47). After the binding to IgRs, luminal antigens cross the barrier in the form of immune complexes (ICs) (29). IgA is the most representative Ig isotype at the mucosal interface, and it is secreted in the intestinal lumen through polymeric $\operatorname{Ig} R(\mathrm{p} \operatorname{Ig} \mathrm{R})$ in the dimeric form of $\operatorname{sg} \mathrm{A}$ (48). $\operatorname{sig} \mathrm{A}$ represents one of the mechanisms exerted by intestinal barrier to control the interaction of microbial and food antigens with the intestinal lumen (29). Despite the usual basal-to-apical secretion pathway of the sIgA (48), in some pathological conditions, an abnormal retro-transport of sIgA ICs can allow the entry of luminal antigens in the intestinal mucosa (29). The IgA-mediated retro-transport of pathogenic bacteria is beneficial for bacterial clearance and intestinal homeostasis (49). The same mechanism applied to non-pathogenic antigens, such as food antigens, could be deleterious rather than protective (48). One of the most common examples of the aforementioned mechanism is celiac disease (CD), an enteropathy induced by the abnormal activation of $\mathrm{T}$ cells by gluten-derived gliadin peptides (50). The high proline content of gliadin prevents their efficient digestion and leads to the release of large immunogenic peptides that cause CD (51). The ectopic expression of the transferrin receptor CD71 at the apical surface of IECs of CD patients allows the retro-transport of sIgA/gliadin IC into the lamina propria (29). On the contrary, in healthy individuals, CD71 is expressed on basolateral membrane of IECs and this permits gliadin peptides to be almost totally degraded (52). Also, IgEs are involved in transcytosis of food antigens due to the expression of their receptor, CD23, at the apical side of enterocytes (53). Increased expression of this receptor can drive the transport of IgEs/allergen ICs from the intestinal lumen to the lamina propria causing mast cell degranulation and allergic inflammatory reactions (54).

\section{REGULATION OF THE INTESTINAL BARRIER FUNCTION BY NUTRITIONAL MEANS}

Food is not only a source of nutrients but may also modulate some physiological functions of the body. This is especially true for the intestinal tract because of the continuous interaction of the intestine with dietary antigens (55). Recent studies demonstrated the effects of the interaction between food and IECs. In fact, dietary antigens are able to modulate transporter activity, TJ permeability, metabolic enzyme expression, immune functions, and microbiota (56). 


\section{Food Regulation of Transporters and lon Channel Function}

Absorption of nutrients is mainly located in the small intestine, while maintenance of fluid-ion homeostasis mostly happens in the large intestine. This process is regulated by transporters and ion channels localized on the enterocytes membrane.

Glucose absorption in the small intestine is strictly regulated by glucose transporters in IECs that are distinguished as sodium dependent (SGLT1) and sodium independent (GLUT2, 3, 5) (57). The inhibition of these transporters is induced by some food derivates, such as polyphenolic compounds [tannic acid, chlorogenic acid, catechins, in particular, epigallocatechin gallate (EGCG)] $(58,59)$ and gymnemic acid, a taste-modulating triterpene glucoside extracted from the leaves of Gymnema sylvestre (60). Also, calcium uptake by specific transporters located on the IECs is regulated by diet compounds (61). For example, enhanced calcium uptake is observed with whey protein digest though the mechanism is not defined at all (62).

Furthermore, most of the ion channels present in epithelial cells are regulated by the levels of cyclic nucleotides, especially cAMP. Food indirectly regulates the levels of cAMP by augmenting the secretion of some hormones $(63,64)$, such as guanylin and natriuretic peptides, that increase cAMP levels. cAMP can directly bind to cyclic nucleotide-gated ion channels (CNG channels) and induce the influx of calcium ions into the cells (65). It can also inhibit the activity of sodium-hydrogen exchanger3 (NHE3), thus preventing the absorption of sodium ions, chloride ions, and water by the epithelium (66-68).

\section{Food Regulation of TJ Permeability}

Tight junctions are not static but highly dynamic structures constantly shaped due to interactions with internal/external stimuli, such as cytokines, growth factors, food residues, and pathogenic and commensal bacteria (56).

Food substances can act by increasing or decreasing TJ permeability, as described in Figure 2 and summarized in Table 1. One of the most common parameters to evaluate the intestinal permeability, as will be described later, is transepithelial electrical resistance (TER) that measure paracellular ions flux (69). Among the food-derived compounds able to modulate the intestinal barrier function, there are some amino acids. Glutamine (Gln) represents the primary source of amino acids for the intestinal mucosa (17). It was demonstrated that Gln improves intestinal barrier function in highly stressed patients (70) and in animal models of endotoxin-induced permeability (71). Also, Gln can restore stress-induced loss of barrier integrity by increasing TER (72). The increase in permeability was confirmed in another work in which Caco-2 cells were deprived of Gln by a combination of a Gln-free media and the inhibition of Gln synthetase (73).

The barrier impairment is caused by the perturbation of TJ protein (ZO-1, occludin, and claudin-1) expression and distribution. These mechanisms are mediated by the PI3K/Akt pathway since the genetic knockdown or pharmacological inhibition of $\mathrm{PI} 3 \mathrm{~K}$ is able to neutralize TER reduction induced by Gln deprivation (74). Furthermore, Gln can also prevent the negative effects of acetaldehyde, an oxidized metabolite of ethanol, avoiding the redistribution of ZO-1 and occludin. This action requires the activation of EGF receptor (75). Another amino acid, tryptophan (Trp), reduces intestinal permeability by increasing TER in Caco-2 cells in a dose-dependent manner even if the molecular mechanism is not yet known (76). Furthermore, peptides derived from cheese and milk proteins have been shown to suppress intestinal permeability. $\beta$-casein peptide increases both occludin expression and TER in Caco-2 (77), while $\beta$-lactoglobulin induces an increase in TER likely due to changes into the cytoskeletal structure. In fact, treatment of cells with cytochalasin D (able to disrupt the cytoskeleton) inhibits TER increase induced by $\beta$-lactoglobulin (78).

Also, some vitamins show protective effects on intestinal permeability. For example, vitamin $\mathrm{D}$ enhances the expression of TJ (ZO-1 and claudin-1) and adherent junction (E-cadherin) proteins (79). Vitamin D is also able to prevent dextran sodium sulfate (DSS)-induced decrease in TER both in vitro and in vivo models in a vitamin D receptor (VDR)-dependent manner (79). In fact, VDR knockout mice exhibits more severe colitis as compared to wild-type mice due to earlier intestinal barrier defects than wild-type mice, as indicated by TER and TJ proteins expression. Retinol, an alcohol form of vitamin A, partially attenuates the decreases in TER induced by Clostridium difficile toxin A in intestinal Caco-2 cells (80). However, the underlying mechanism remains to be elucidated.

Polyphenols participate in the regulation of the intestinal barrier too. The flavonoid subgroup, quercetin, myricetin, and kaempferol, enhances barrier integrity in intestinal Caco- 2 cells (17). Quercetin, the most common flavonoid in nature, increases TER and reduces paracellular flux across Caco- 2 monolayers in a dose-dependent manner $(81,82)$. This mechanism is accompanied by an increase in claudin- 4 expression and the assembly of ZO-2, occludin, and claudin-1 at the TJ level. Also, kaempferol increases TER due to promotion of the cytoskeletal association of ZO-1, ZO-2, occludin, claudin-1, claudin-3, and claudin-4 and an increase in the expression of some TJ proteins (83). The isoflavonoid genistein inhibits the redistribution and the dissociation of occludin/ZO-1 complex protecting barrier integrity against acetaldehyde and oxidative stress $(84,85)$.

On the contrary, other food compounds negatively regulate intestinal barrier, e.g., gliadin whose effect correlates with CD (86), as previously discussed. Gliadin binds to CXCR3 on IECs and increases intestinal permeability by a MyD88-dependent release of zonulin (87). Zonulin interacts with a specific surface receptor activating phospholipase $\mathrm{C}$ that hydrolyzes phosphatidyl inositol releasing inositol 1,4,5-trisphosphate (IP3) and diacylglycerol (DAG) (88). DAG and PPI-3 can directly and indirectly (through the release of intracellular $\mathrm{Ca}^{2+}$ ), respectively, activate protein kinase $\mathrm{C}$ (PKC). Activated PKC catalyzes the phosphorylation of target proteins with subsequent polymerization of soluble $\mathrm{G}$-actin in F-actin. This polymerization causes the rearrangement of the filaments of actin and the subsequent displacement of proteins, including ZO-1 from the junctional complex. As a result, intestinal TJs become looser allowing the paracellular passage of gliadin from the intestinal lumen to the lamina propria (89). Ex vivo experiments on C57BL6 and CXCR $3^{-1-}$ mice confirmed these observations. Intestinal segments exposed to gliadin from 


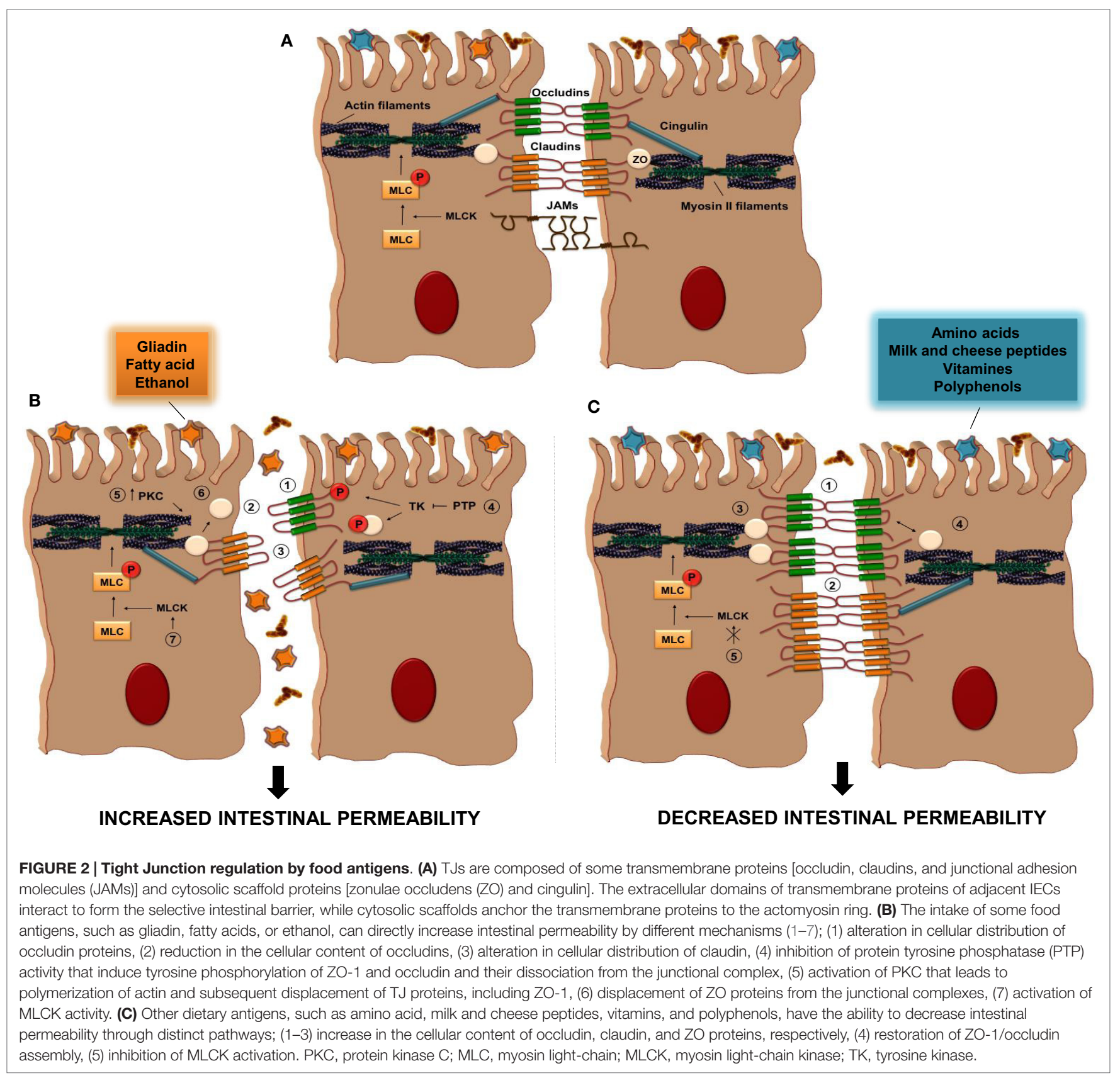

wild-type but not from CXCR3 ${ }^{-/-}$mice increase zonulin release and intestinal permeability (87). Furthermore, it has recently been demonstrated by in vivo intravital microscopy that gliadin modulates intestinal permeability inducing a redistribution of ZO-1 (90).

Middle-chain fatty acids (MCFAs), e.g., capric acid and lauric acid and long-chain fatty acids [LCFAs, e.g., eicosapentaenoic acid (EPA), $\gamma$-linoleic acid, and docosahexaenoic acid (DHA)] are also able to increase TJ permeability by reducing TER (91, 92). The barrier properties of the latter are controversial since it was discovered that, unlike the finding in $\mathrm{Caco} 2$ cell monolayer, EPA and DHA were particularly effective in supporting barrier integrity. In a different cell line (T84 cell), administration of
EPA and DHA improves resistance and reduces IL-4-mediated permeability (93). Capric acid, but not lauric acid, induced the redistribution of TJ proteins (occludin and $\mathrm{ZO}-1$ ) and the rearrangement of the cytoskeleton actin (94). This means that these two MCFAs act with a different mechanism (95). The common ground is the paracellular permeability induced by both acids that requires intracellular $\mathrm{Ca}^{2+}$-dependent myosin light chain kinase (MLCK) activation (95). Short-chain fatty acids (SCFAs) also modulate intestinal barrier. The SCFAs, such as acetate, propionate, and butyrate, are the major anions in the colon and are mainly produced by bacterial fermentation of undigested carbohydrates. Butyrate strengthens the barrier through the increase among TER, ZO-1/ZO-2, and 
TABLE 1 | Effect of diet-derived compounds on intestinal permeability.

\begin{tabular}{|c|c|c|c|c|c|}
\hline Dietary antigens & $\begin{array}{l}\text { Effect on } \\
\text { permeability }\end{array}$ & $\begin{array}{l}\text { TER } \\
\text { measurement }\end{array}$ & Mechanisms of action & Models of study & Reference \\
\hline \multicolumn{6}{|l|}{ AMINO ACIDS } \\
\hline Gln & Decreased & Increased & Unknown & Caco2 cell line & (66) \\
\hline Gln deprivation & Increased & Not determined & $\begin{array}{l}\text { Reduction of occludin, claudin-1, and ZO-1/ } \\
\text { redistribution of claudin-1 and occludin }\end{array}$ & Caco2 cell line & (67) \\
\hline Trp & Decreased & Increased & Unknown & Caco2 cell line & $(70)$ \\
\hline \multicolumn{6}{|l|}{ PEPTIDES } \\
\hline$\beta$-casein & Decreased & Increased & Increase occludin expression & Caco2 cell line & (71) \\
\hline$\beta$-lactoglobulin & Decreased & Increased & Modifications into the cytoskeletal structure & Caco2 cell line & $(72)$ \\
\hline \multicolumn{6}{|l|}{ VITAMINS } \\
\hline Vitamin D & Decreased & $\begin{array}{l}\text { Increased (in } \\
\text { Caco2 cell line) }\end{array}$ & $\begin{array}{l}\text { Enhancement of claudin-1, ZO-1 and E-cadherin } \\
\text { proteins expression }\end{array}$ & $\begin{array}{l}\text { SW480-Caco } 2 \text { cell lines/NDR }{ }^{+/+} \text {and } \\
\text { VDR }^{-/-} \text {in C57BL6 background }\end{array}$ & $(73)$ \\
\hline Retinol (vitamin A) & Decreased & Increased & Neutralization Clostridium difficile toxin A & Caco2 cell line & $(74)$ \\
\hline \multicolumn{6}{|l|}{ POLYPHENOLS } \\
\hline Quercetin & Decreased & Increased & $\begin{array}{l}\text { Increase in claudin-4 expression and in ZO-2, } \\
\text { occludin and claudin-1 assembly }\end{array}$ & Caco2 cell line & $(75,76)$ \\
\hline Kaempferol & Decreased & Increased & $\begin{array}{l}\text { Promotion of ZO-1/2, occludin and claudin-1/3/4 } \\
\text { cytoskeletal association }\end{array}$ & Caco2 cell line & $(77)$ \\
\hline \multirow[t]{2}{*}{ Genistein } & Decreased & Increased & $\begin{array}{l}\text { Inhibition of the redistribution and the dissociation of } \\
\text { occludin/ZO-1 complex }\end{array}$ & Caco2 cell line & $(78,79)$ \\
\hline & Decreased & Increased & Inhibition of TNF $\alpha$-mediated effects & HT-29/B6 cell line & (99) \\
\hline EGCG & Decreased & Increased & Inhibition of INF $\gamma$-mediated effects & T84 cell line & (98) \\
\hline Curcumin & Decreased & Increased & Inhibition of TNF $\alpha$ - and IL-1 $\beta$-mediated effects & Caco2 cell line & $(100,101)$ \\
\hline \multicolumn{6}{|c|}{ DITERPENE GLYCOSIDE } \\
\hline Capsianoside & Increased & Decreased & Changes in $F / G$ actin ratio & Caco2 cell line & $(92)$ \\
\hline \multicolumn{6}{|l|}{ LCFAs } \\
\hline EPA and DHA & $\begin{array}{l}\text { Increased } \\
\text { Decreased }\end{array}$ & $\begin{array}{l}\text { Decreased } \\
\text { Increased }\end{array}$ & $\begin{array}{l}\text { Protein kinase } \mathrm{C} \text { regulation/unknown } \\
\text { Reduction of IL-4-mediated permeability }\end{array}$ & $\begin{array}{l}\text { Caco } 2 \text { cell line } \\
\text { T84 cell line }\end{array}$ & $\begin{array}{c}(84,85) \\
(86)\end{array}$ \\
\hline \multicolumn{6}{|l|}{ MCFA } \\
\hline $\begin{array}{l}\text { Capric acid } \\
\text { Lauric acid }\end{array}$ & $\begin{array}{l}\text { Increased } \\
\text { Increased }\end{array}$ & $\begin{array}{l}\text { Decreased } \\
\text { Decreased }\end{array}$ & $\begin{array}{l}\text { Redistribution of occludin and ZO-1/MLCK activation } \\
\text { MLCK activation }\end{array}$ & $\begin{array}{l}\text { Caco2 cell line } \\
\text { Caco2 cell line }\end{array}$ & $\begin{array}{l}(87) \\
(88)\end{array}$ \\
\hline \multicolumn{6}{|l|}{ SCFAs } \\
\hline $\begin{array}{l}\text { Acetic and } \\
\text { propionic acids }\end{array}$ & Decreased & Increased & Activation of PI3K & Caco2/T84 cell lines & $(90)$ \\
\hline \multicolumn{6}{|l|}{ MINERALS } \\
\hline Zinc depletion & Increased & Decreased & $\begin{array}{l}\text { Redistribution of occludin, ZO-1, E-cadherin, and } \\
\beta \text {-catenin and F-actin }\end{array}$ & Caco2 cell line & (93) \\
\hline \multicolumn{6}{|l|}{ ALCOHOLS } \\
\hline Ethanol & Increased & Decreased & Redistribution of occludin and ZO1/MLCK activation & Caco2 cell line & $(94)$ \\
\hline Acetaldehyde & Increased & Decreased & $\begin{array}{l}\text { Loss of interaction between occludin/ZO-1 and } \\
\beta \text {-catenin/E-cadherin by a tyrosine phosphorylation- } \\
\text { dependent mechanism }\end{array}$ & $\begin{array}{l}\text { Caco } 2 \text { cell line/Sprague-Dawley } \\
\text { rats and } \mathrm{C} 3 \mathrm{H} / \mathrm{He} \text { mice }\end{array}$ & $(79,95-97)$ \\
\hline Chitosan & Increased & Decreased & Redistribution of ZO-1 and F-actin distribution & Caco2 cell line & $(91)$ \\
\hline
\end{tabular}

cingulin protein in rat-1 fibroblasts (96). Acetic and propionic acids from diet increased TER and decreased permeability to lucifer yellow in a dose-dependent manner in the rat colon and intestinal cells (97). The acetic acid-mediated increase in TER could be suppressed by the pharmacological inhibition of PI3K (97).

Apart from fatty acids, there are other food compounds that negatively regulate barrier function. Chitosan, a polysaccharide widely used in the food industry, is able to increase paracellular permeability by altering the distribution of ZO-1 and F-actin (98). Moreover, sweet pepper extract decreases TER, and this effect is likely mediated by capsianoside, its active compound, that induces dysfunctional TJs by changing the F-actin and G-actin ratio (99).
Zinc is essential for the survival and function of the cells and its depletion increases intestinal permeability by reducing TER and altering the expression of ZO-1, occludin, and F-actin filaments (100). Alcohol and its oxidized metabolite, acetaldehyde, impair intestinal barrier function. Ethanol decreases TER and increases mannitol flux due to a redistribution of ZO-1 and occludin (101) and barrier impairment seems to be caused by a MLCK-dependent mechanism. Administration of acetaldehyde in vivo induces an impairment of barrier integrity, as indicated by TER decrease and improved dextran permeability (102). In vitro studies show that the underling mechanism acts via a tyrosine kinase-dependent mechanism $(85,103)$. The suppression of protein tyrosine phosphatase (PTP) activity by acetaldehyde causes tyrosine phosphorylation of ZO-1, occludin, E-cadherin, and $\beta$-catenin and their 
dissociation from the respective $\mathrm{TJ}$ and $\mathrm{AJ}$ complexes, finally leading to increased paracellular permeability $(85,104)$.

Food components can regulate TJ permeability not only directly by targeting signal transduction pathways involved in TJ regulation but also indirectly by influencing cytokine signaling involved in this modulation (17). For example, epigallocatechin-3-gallate (EGCG), the predominant polyphenol in green tea, does not affect epithelial permeability when administered alone to confluent T84 cells (105). On the contrary, the administration of this polyphenol in combination with IFN $\gamma$ prevents the negative effects of this cytokine on epithelial permeability (105). Furthermore, genistein inhibits the tumor necrosis factor $\alpha(\mathrm{TNF} \alpha)$-mediated TER reduction in HT-29/B6 cells (106). Finally, it was demonstrated that another polyphenol, curcumin, is able to block TNF $\alpha$ - and inteleukin-1 $\beta$ (IL-1 $\beta$ )-induced NF- $\kappa B$ activation, increasing TER and reducing intestinal permeability $(107,108)$.

\section{Food Regulation of Intestinal Detoxification Systems}

Detoxification systems in IECs are activated after the binding of xenobiotic to intracellular receptors [e.g., the arylhydrocarbon receptor $(\mathrm{AhR})$ and the pregnant $\mathrm{X}$ receptor $(\mathrm{PXR})$ ] and the subsequent entry into the nucleus that induce the expression of some detoxification enzymes (109). These enzymes are involved in the oxidation and conjugation of xenobiotics. They are also involved in the excretion of harmful compounds from the cells (110). It was demonstrated that some flavonoids and terpenoids are able to induce PXR-dependent transcriptional activity activating the intestinal detoxification system (111). Moreover, dietary flavonoids can help to balance the ratio between activation and suppression of detoxification enzymes to avoid the possibility that a helpful mechanism could become detrimental by reducing the bioavailability of drugs and functional foods (56).

\section{Food Regulation by Microbiota}

The microbiota is involved in several functions crucial for the host homeostasis. These include metabolic homeostasis and cross talk with the immune system. The metabolic function is fundamental, as the bacterial degradation of some complex nutrients from food is the source of essential amino acids and vitamins (112). In fact, human enzymes cannot degrade the most complex carbohydrates and plant polysaccharides (113). Among the metabolites produced during the process, there are some essential products absorbed by the host. These include vitamins, such as vitamin $\mathrm{K}$, and most of the water-soluble B vitamins, such as biotin, cobalamin, and riboflavin $(114,115)$. Furthermore, other metabolites produced by microbiota are the SCFAs (as previous discussed), fermentable carbohydrates, and resistant starches, which are not broken down in the upper digestive tract (116). Fermentation of these substrates also results in the production of gases, including hydrogen, methane, and hydrogen sulfide.

In addition, the intestinal microbiota is involved in the activation/inactivation of bioactive food compounds, such as isoflavanoid and plant lignans (112). In fact, a metabolic transformation, including deglycation and hydrolysis, is required for many plant polyphenols to induce their biologically active form. Within the colon, polyphenols are broken down by the microbiota to a variety of small phenolic components whose physiological relevance is not yet fully known (117). In addition, recent studies demonstrated that microbiota composition could be selectively modulated by polyphenol (118). Therefore, the positive effects associated with polyphenols consumption $(105,119,120)$ should not only be attributed to their bioactive metabolites but also to the modulation of the intestinal microbiota.

Microbiota is also able to convert prodrugs into their bioactive forms and to modify xenobiotics and bile acids with potential effects on the GI motility, secretion, and immune function (112). These effects are also due to bile acids contribution to the modulation of microbiota composition (121). Among harmful products of protein fermentation, hydrogen sulfide might be relevant for compromising intestinal health. In fact, it can be converted to thiosulfate and further oxidized to tetrathionate during inflammation. This product supports the growth of tetrathionate utilizing pathogens, many of which have been associated with the intestinal symptoms of irritable bowel syndrome (IBS) patients (122).

The metabolic function of the microbiota can result in opposite effects based on the dietary content. Diets containing fermentable fibers increase SCFA-producing bacteria. The produced SCFAs in turn protect the epithelium by acting on the intestinal barrier. Specifically, these diets increase TJ protein production and TER and decrease permeability and bacterial translocation. SCFAs also stimulate IEC metabolism, turnover, and apoptosis (123). A similar effect can be described for diets enriched in probiotic bacteria. On the contrary, diets that favor growth of pathogenic or opportunistic bacteria (as with intake of milk fat) would have opposite effects, compromising barrier integrity by altering TJ proteins production and distribution, and decreasing TER. These effects finally result in increased barrier permeability boosting bacterial translocation (124).

\section{IN VITRO AND IN VIVO MODELS TO STUDY INTESTINAL PERMEABILITY}

Gold standards to measure intestinal permeability are the measurement of TER for in vitro study and the intestinal permeability test (IPT) for in vivo study (29). TER measurement is an easy-toperform technique to investigate both the functional expression and the regulation of TJs (69). To perform measurements, cells are cultured as monolayers on commercially available permeable filter supports. To better mimic the physiological epithelial cell layer filter, supports have been designed with different pore densities and pore diameters (125). The most frequently used cellular line to study intestinal permeability is Caco-2. This line derives from human epithelial colorectal adenocarcinoma cells $(73,81$, 107 ) and when cultured in appropriate conditions is able to create a monolayer of cells with a luminal and basolateral polarization. Apart from the measurement of TER, in vitro studies also included the evaluation of the effects of human biopsy extracts on permeability to fluorescein isothiocyanate (FITC)-dextran in confluent monolayers of Caco-2 cells. Furthermore, to assess high capacity size and charge selective pathway versus low capacity paracellular route the morphological measurements of 
TJ components in mucosal biopsies and the polyethylene glycol (PEG) profiling were used (126). Moreover, the Ussing chamber technique provides a short-term intestine fragments culture that measure electrical and transport parameters of an intact polarized intestinal epithelium (127). Some concerns with this method are related to the limited viability and function of an $e x$ vivo intestinal preparation and the number of measurements that seem to be under representative for the physiological complexity of the intestinal mucosa (128).

For in vivo models of intestinal permeability, IPT directly measures the ability of two non-metabolized sugar molecules (lactulose and mannitol) to permeate the intestinal mucosa (129, 130). The degree of intestinal permeability is expressed by the levels of these two sugars recovered in a urine sample collected over the next $6 \mathrm{~h}$ (127). In fact, in case of barrier function loss these molecules cross the intestinal barrier, enter into the circulation and can be detected in urine after renal excretion. IPT can discriminate between paracellular (lactulose) and transcellular (mannitol) pathways in vivo, and it is a useful test in clinical studies because it gives information on the overall status of the intestine (villous atrophy and inflammation) (29). For research purpose, to study intestinal permeability in vivo, experimental animal models can be used. It is possible to test the presence of macromolecular tracers (dextrans or Evans Blue) in the blood after gavage (29). But with this procedure, several parameters that significantly affect the measurement of intestinal permeability, such as gastrointestinal (GI) motility affecting the time of contact of the tracer with the mucosa and body distribution of the tracers, are not be taken into account. For this reason, to measure intestinal permeability in animal models, intestinal loop systems and tracer recovery in mesenteric or portal blood could be preferred even if they require longer and more invasive procedures (131).

\section{FOOD REGULATION OF INTESTINAL INFLAMMATION: COOPERATION BETWEEN DIET, IMMUNE SYSTEM, AND MICROBIOTA}

Together with the IECs, there are at least two other important components to be taken into account for the regulation of intestinal permeability: one internal and one external. The intestinal immune system accounts for the internal side of the barrier, while the microbiota represents the external one (132). Intestinal immunity is characterized by numerous dynamic responses that contribute to maintain the delicate balance between the capacity of mounting protective immune responses against infectious agents and the ability to tolerate innocuous antigens present in the intestinal lumen (133). The intestinal barrier is not completely impermeable to macromolecules. In fact, in the steady state, the transepithelial passage of small amounts of food-derived antigens and microorganisms participates in the induction of the homeostatic/tolerogenic immune response toward food antigens and commensal bacteria $(12,134)$. The mucosal immune system of the GI tract is composed of distinct immune cell types, such as neutrophils, monocyte/macrophages, DCs, mast cells, innate lymphoid cells, B, and T cells (135). The intestinal immune system regulates mucosal barrier function by different mechanisms: the modulation of epithelial dynamics, the regulation of AMPs production, the influence on the microbiota, and the induction of a response against microorganisms and luminal antigens that cross the barrier (13). Cytokines secreted by immune cells have been described as mediators involved in the regulation of mucosal barrier function at various levels, including the epithelial integrity and the immune response $(136,137)$. For example, TNF $\alpha$, among the major players involved in the inflammatory process, augments paracellular permeability by removing claudin 1 from TJs, increasing claudin 2 expression, and enhancing occludin degradation (138). The inflammatory response can also be modulated by some amino acids. Taurine, one of the most abundant free amino acid in mammals, exerts anti-inflammatory functions both in vivo and in vitro $(139,140)$. The effects are mediated by taurine transporters (TAUT) whose synthesis and activity are increased in response to external stresses [e.g., osmotic pressure (141) and inflammatory cytokines $(142,143)]$ due to the necessity to maintain high intracellular level of this amino acid. Zhao et al. demonstrated that taurine supplementation reduces weight loss, diarrhea severity, colon shortening, and induces an increase in colonic tissue myeloperoxidase activity after DSS treatment (140). They also proved that taurine was able to inhibit the secretion of macrophage inflammation protein-2 (MIP-2) from IECs and the infiltration of inflammatory cells, such as neutrophils (140). Furthermore, several plant-derived polyphenols have been described as modulators of the inflammatory response $(82,119$, $120,144)$. Their effect is likely mediated by the selective suppression of the inflammatory response of intestinal DCs. Possibly, the DCs mostly affected by the polyphenol exposure are those projecting dendrites into the intestinal lumen (33-35) where these compounds are more abundant.

The microbiota greatly influences mucosal barrier function both by direct and indirect modulation of the epithelial layer and mucosal components $(145,146)$. Specifically, a role in the regulation of intestinal permeability must be considered for some important microbiota components, i.e., probiotics and prebiotics. Probiotics are defined by the World Health Organization as "live organisms which, when administered in adequate amounts, confer a health benefit on the host" (147). Probiotics are non-pathogenic bacteria that are derived from the alimentary tract and are able to improve host colonic microenvironment (123). The precise probiotics mechanism of action has yet to be fully clarified. Potential mechanisms on the epithelial barrier include a limited bacterial movement across the mucus layer through increasing mucin expression and secretion by goblet cells, an increased production of AMPs, and an enhanced TJs stability. Overall, these mechanisms reduce epithelial permeability to intraluminal pathogens and toxins (148). Furthermore, probiotics influence mucosal immunity by increasing levels of IgA-producing cells in the lamina propria and promoting secretion of sIgA into the luminal mucus layers avoiding bacteria colonization of the epithelium (148). Through a cascade of signaling events, probiotics enhance the production and secretion of anti-inflammatory cytokines, including IL-10 and transforming growth factor $\beta$ (TGF $\beta$ ) by T Regs (117). In small animal models, several reports have suggested that probiotics enhance the local and systemic immune system through an 
increased activity of IgA, T-cells, macrophages, T helper1 (Th1)cytokines, as well as the modulation of gut-associated lymphoid tissue, and natural killer cell cytotoxicity (149). Probiotics might also affect the intestinal microbiota and hence limit intestinal bacteria overgrowth and the production of lipopolysaccharides (123).

The beneficial effects of probiotics have been reported in several situations, such as food allergies (150), immune disorders (151), prevention of intestinal tumors (152), prevention of body weight loss in animal models (153), and IBD (154). In fact, probiotics have gained big interest during the last decade as treatments to maintain intestinal homeostasis and reduce specific GI symptoms (155). Although it has been demonstrated that the use of probiotics in humans is relatively safe, some studies have questioned about the administration of a huge quantity of bacteria into a host (156). To avoid this potential risk, instead of using the whole live microorganisms, only probiotic-derived beneficial molecules have been administered. For example, a recombinant $40 \mathrm{kDa}$ soluble protein derived from Lactobacillus rhamnosus GG (LGG) was able to reproduce the antiapoptotic effect of the bacterium in vitro (157). Importantly, the delivery of LGGp40 to the colon in vivo using a pectin/zein hydrogel bead system was able to ameliorate DSS-induced intestinal injury as well as oxazolone-induced Th2-driven colitis (157).

On the other hand, prebiotics are non-digestible food components that contribute to host health by inducing specific changes in the composition and in the activity of intestinal microflora (158). They are fermented oligosaccharides, such as fructooligosaccharides, galactooligosaccharides, lactulose, and inulin, which stimulate the growth of beneficial gut bacteria (159). Due to their composition, they can only be absorbed in the colon, where they ferment into SCFAs and lactate (160), which are crucial energy sources for the host (161). The efficacy of prebiotics in IBD has been studied in vitro (162) and in animal models (DSS- and TNBS-induced colitis) $(163,164)$. However, there are few human studies limited by a small number of patients (165). For example, in a recent study, UC patients were treated with mesalazine and randomly assigned to receive either oligofructose-enriched inulin or placebo. Authors showed that the supplemented groups had lower fecal calprotectin than controls. As fecal calprotectin is an inflammatory marker, they concluded that prebiotics can reduce inflammation in UC patients (166).

Since probiotics are becoming a new therapeutic option, it is necessary to determine which strains have the greatest efficacy, if they are more effective alone or in conjunction with other pro or prebiotics, and what is their half-life in the GI tract. In fact, it is likely that a combined treatment with probiotics and prebiotics, called synbiotic therapy, can have a stronger effect on intestinal diseases than probiotics or prebiotics alone (123). It is also likely that the probiotic, prebiotic, or synbiotic combination will not be suitable for all patients, but the treatment will depend on the individual microbiota composition (123).

In agreement with the effect of the microbiota on the intestinal permeability, a novel treatment option for IBD has gained interest, i.e., fecal microbiota transplantation (FMT) (167). Fecal transplantation (or bacteriotherapy) is the transfer of stool from a healthy donor into the GI tract of a patient. This strategy has been originally designed for the treatment of recurrent $C$. difficile colitis (168). C. difficile colitis is a complication of antibiotic therapy that may be associated with diarrhea, abdominal cramping, and sometimes fever (168). FMT appears to be the most effective intervention available for refractory $C$. difficile infection (rCDI). In fact, metronidazole, vancomycin, and fidaxomycin (antibiotics used for the treatment of this infection), fail in $30 \%$ of treated individuals, causing a relapse of the infection (168). This was clearly demonstrated by an important paper describing a clinical trial that used FMT for rCDI (169). A total of 120 patients were enrolled, and they were treated with fecal transplant or vancomycin. The trial was interrupted in advance due to the difference between the two groups. Indeed, fecal transplant was three to four times more effective in eradicating the infection compared to the antibiotic. Fecal infusions cured 13 out of 16 patients (81\%), whereas only 7 out of 26 patients (27\%) treated with vancomycin obtained the same result (169). Thus, FMT has been shown to be effective in treating relapsing or rCDI, but practical barriers and safety concerns have limited its widespread use (170). The majority of reported FMT procedures have been performed with fresh stool suspensions from related donors using delivery by colonoscopy. The use of fresh donations requires prior identification and screening of a suitable donor, thus precluding the use of FMT in acute situations (170). Donor selection is a crucial aspect for FMT. In fact, higher compliance has been reported if FMT is allowed from a donor chosen by the patient. Nonetheless, donations from healthy volunteer donors obtained by an unbiased selection resulted in lower incidence of viral infections and better genetics of the microbiota (171). In fact, it has been reported the case of a woman successfully treated with FMT with stools from a healthy but overweight donor that, later, developed new-onset obesity. The link between obesity and FMT transplant could be the result of multiple factors, including the resolution of CDI with subsequent increased appetite and the concurrent treatment of Helicobacter pylori. Nonetheless, the same has been observed in animal models that acquired an obese phenotype following the transplant of the microbiota from an obese donor (172). Furthermore, it is likely that the weight gain in the case reported was influenced by a combination of genetic factors derived from the donor and recipient microbiota (173).

It was recently described the successful use of frozen FMT inocula for the treatment of CDI. Carefully screened healthy volunteer donors were used to create capsules that prevent the need for invasive procedures for FMT administration, avoid procedure-associated complications, and significantly reduce the cost of the treatment (170). The major limitation of this study is the small sample size, the lack of placebo or active comparator, and the short follow-up that precludes the assessment of long-term immunological effects and onset of latent infections (170). Currently, several aspects limit the scientific value of the described protocol; nonetheless, it is a groundbreaking trial that will hopefully be validated in the near future.

Results from these analyses suggest that FMT is generally tolerable and safe. In fact, symptoms, such as a predominantly self-limiting fever, can be considered a consequence of the administration procedures themselves. Rigorous screening of the donor and donor stool remains particularly important to implement FMT efficacy (167). The approach to FMT in IBD is 
still in its infancy, and much work remains to be done in order to clarify its ultimate utility. After all, the most efficient FMT delivery strategy and frequency, as well as the definition of an exact mix of prebiotics and probiotics to be transplanted remains to be further investigated (167).

\section{CONCLUDING REMARKS}

Increased intestinal permeability can be related to different mechanisms; the opening of pores in the tight junctional complexes, an increased rate of transcytosis of antigens or ICs, the final stage of inflammation, apoptosis, and ulceration. All of these mechanisms cause the entry of luminal antigens into the lamina propria leading to the initiation of inflammatory immune responses that, if protracted, could become a chronic intestinal inflammatory syndrome. Indeed, a common feature of the intestinal diseases is the failure to contain the luminal content. Paracellular or transcellular pathways lead to chronic inflammation if not correctly regulated. Although the majority of dietary proteins are totally degraded by digestive enzymes and are absorbed in the form of nutrients, some can resist both the low $\mathrm{pH}$ of the gastric fluid and proteolytic enzyme hydrolysis. This means that large immunogenic peptides or intact proteins are capable of reaching the intestinal lumen by the different pathways described before. Intestinal barrier function is regulated by multiple components. Among these, an emerging role is depicted for nutrition. The role of different dietary antigens in the regulation of intestinal permeability is in part contradictory. While some compounds such as gliadin impair the TJ barrier ultimately leading to $\mathrm{CD}$, others such as Gln and polyphenols enhance and protect TJ barrier integrity. The latter category of food could be used as therapeutic tools for diseases associated with barrier defects. The effects of dietary compounds as preventive or therapeutic agents in different intestinal diseases have to be studied taking into account the complexity of the intestinal environment. The integrity of the epithelial cell monolayer is one of the players involved, and, at the moment, we still largely ignore whether barrier defects are the trigger or the effect of chronic inflammatory syndromes. A further level of complexity is determined by the variety of modifications that change the chemical structure of the nutritionally derived compounds along the way through the intestine.

Composition of dietary intake can have significant impact on the microbiota, and consequently on the epithelial barrier. Considering bacteria fermentation, diets enriched in milk fat can promote the increase in barrier permeability and bacterial translocation along with the decrease in TJ proteins and TER. On the contrary, diets, including probiotic bacterial species or prebiotic fibers, strengthen the epithelial barrier by increasing TJ proteins and TER and decreasing permeability and bacterial translocation, thus, preventing or ameliorating the inflammatory state. It remains to be determined by the link between nutrition and microbiota composition. This is a challenging task as the influence of factors, such as genetics, hygiene, and living conditions, are not taken into account in studies comparing distinct populations.

Understanding the intricate relationship between epithelial barrier, microbiota, and diet will contribute to design new preventive/therapeutic approaches for GI diseases, particularly IBD. This is becoming in part true if we consider the use of fecal therapy instead of classical antibiotics treatment for $\mathrm{rCDI}$. Nonetheless, this new therapeutic approach needs to be further investigated, in particular, for the definition of precise parameters for the donor choice.

Deep analysis of the microbiota is now possible due to faster sequencing techniques and improved bioinformatics tools even if the major challenge remains the ability to discriminate between healthy and disease microbiota state. In fact, substantial inter- and intra-individual variations in addition to age-related changes in the composition of the intestinal microbiota were identified providing an additional level of complexity to this intricate pattern.

In the recent years, the challenge for the human race was to obtain enough food to provide sufficient nutrients to the body. Nowadays, in vast regions of the planet, the challenge is to sustain the body with the right combination of nutrients able to prevent chronic inflammatory syndromes. We knew the importance of the intestinal permeability, we then realized the importance of the cross talk between the intestinal epithelium and the immune system, and we are just starting to realize the pivotal role of the microbiota for human health. A further level of complexity will need to be addressed in the near future; in particular, we will need to understand the cascade of events that lead to chronic inflammatory syndromes. In vitro studies are still required to dissect the effects of single nutritional components as well as their effects when combined. Animal models will be required to better understand the effects of nutritional strategies for the prevention/ treatment of chronic inflammatory syndromes. We still need to shed light on the axis between microbial communities and the nutritional intake as well as on the axis between microbial communities and post-modifications of the nutritional compounds. These modifications may severely impact the biological effects of the nutrients. Finally, in light of what was discovered by Fonseca and others (174), trials based on food components as complementary approach, should consider a working hypothesis made of three consecutive steps. The first should be an antibiotic approach to eliminate the pre-existing microbiota, the second should be the administration of a selected mix of prebiotics and probiotics to create a known microbiota, and then, the final step should be the nutritional intervention.

The switch from acute to chronic disease characterized the last century. Health systems are still adjusting to the need for long term and personalized medicine that will consider nutrition much more than just food intake.

\section{AUTHOR CONTRIBUTIONS}

All authors contributed to the manuscript by constructive discussions and proof reading.

\section{ACKNOWLEDGMENTS}

This work was supported by the Italian Ministry of Health, "GR2011." We thank all members of LAB-81 and Dr. Rosalind Polley for their constructive comments. 


\section{REFERENCES}

1. Farhadi A, Banan A, Fields J, Keshavarzian A. Intestinal barrier: an interface between health and disease. J Gastroenterol Hepatol (2003) 18:479-97. doi:10.1046/j.1440-1746.2003.03032.x

2. Groschwitz KR, Hogan SP. Intestinal barrier function: molecular regulation and disease pathogenesis. J Allergy Clin Immunol (2009) 124:3-20. doi:10.1016/j.jaci.2009.05.038

3. Weiner HL. Oral tolerance, an active immunologic process mediated by multiple mechanisms. J Clin Invest (2000) 106:935-7. doi:10.1172/JCI11348

4. Fasano A, Shea-Donohue T. Mechanisms of disease: the role of intestinal barrier function in the pathogenesis of gastrointestinal autoimmune diseases. Nat Clin Pract Gastroenterol Hepatol (2005) 2:416-22. doi:10.1038/ ncpgasthep0259

5. Miele L, Valenza V, La Torre G, Montalto M, Cammarota G, Ricci R, et al. Increased intestinal permeability and tight junction alterations in nonalcoholic fatty liver disease. Hepatology (2009) 49:1877-87. doi:10.1002/ hep. 22848

6. Bosi E, Molteni L, Radaelli MG, Folini L, Fermo I, Bazzigaluppi E, et al. Increased intestinal permeability precedes clinical onset of type 1 diabetes. Diabetologia (2006) 49:2824-7. doi:10.1007/s00125-006-0465-3

7. Pastorelli L, De Salvo C, Mercado JR, Vecchi M, Pizarro TT. Central role of the gut epithelial barrier in the pathogenesis of chronic intestinal inflammation: lessons learned from animal models and human genetics. Front Immunol (2013) 4:280. doi:10.3389/fimmu.2013.00280

8. DeMeo MT, Mutlu EA, Keshavarzian A, Tobin MC. Intestinal permeation and gastrointestinal disease. J Clin Gastroenterol (2002) 34:385-96. doi:10.1097/00004836-200204000-00003

9. Turner JR. Intestinal mucosal barrier function in health and disease. Nat Rev Immunol (2009) 9:799-809. doi:10.1038/nri2653

10. Kraehenbuhl JP, Pringault E, Neutra MR. Intestinal epithelia and barrier functions. Aliment Pharmacol Ther (1997) 11:3-9. doi:10.1111/j.1365-2036.1997. tb00803.x

11. Schenk M, Mueller C. The mucosal immune system at the gastrointestinal barrier. Best Pract Res Clin Gastroenterol (2008) 22:391-409. doi:10.1016/j. bpg.2007.11.002

12. Rescigno M. The intestinal epithelial barrier in the control of homeostasis and immunity. Trends Immunol (2011) 32:256-64. doi:10.1016/j.it.2011.04.003

13. Sánchez de Medina F, Romero-Calvo I, Mascaraque C, Martínez-Augustin O. Intestinal inflammation and mucosal barrier function. Inflamm Bowel Dis (2014) 20:2394-404. doi:10.1097/MIB.0000000000000204

14. Harrison OJ, Maloy KJ. Innate immune activation in intestinal homeostasis. J Innate Immun (2011) 3:585-93. doi:10.1159/000330913

15. Catalioto RM, Maggi CA, Giuliani S. Intestinal epithelial barrier dysfunction in disease and possible therapeutical interventions. Curr Med Chem (2011) 18:398-426. doi:10.2174/092986711794839179

16. Peterson LW, Artis D. Intestinal epithelial cells: regulators of barrier function and immune homeostasis. Nat Rev Immunol (2014) 14:141-53. doi:10.1038/ nri3608

17. Suzuki T. Regulation of intestinal epithelial permeability by tight junctions. Cell Mol Life Sci (2013) 70:631-59. doi:10.1007/s00018-012-1070-x

18. Furuse M, Hirase T, Itoh M, Nagafuchi A, Yonemura S, Tsukita S, et al. Occludin: a novel integral membrane protein localizing at tight junctions. $J$ Cell Biol (1993) 123:1777-88. doi:10.1083/jcb.123.6.1777

19. Furuse M, Fujita K, Hiiragi T, Fujimoto K, Tsukita S. Claudin-1 and -2 : novel integral membrane proteins localizing at tight junctions with no sequence similarity to occludin. J Cell Biol (1998) 141:1539-50. doi:10.1083/ jcb.141.7.1539

20. Martin-Padura I, Lostaglio S, Schneemann M, Williams L, Romano M, Fruscella P, et al. Junctional adhesion molecule, a novel member of the immunoglobulin superfamily that distributes at intercellular junctions and modulates monocyte transmigration. J Cell Biol (1998) 142:117-27. doi:10.1083/jcb.142.1.117

21. Ikenouchi J, Furuse M, Furuse K, Sasaki H, Tsukita S, Tsukita S. Tricellulin constitutes a novel barrier at tricellular contacts of epithelial cells. J Cell Biol (2005) 171:939-45. doi:10.1083/jcb.200510043

22. Anderson JM, Van Itallie CM. Physiology and function of the tight junction. Cold Spring Harb Perspect Biol (2009) 1(2):a002584. doi:10.1101/cshperspect. a002584
23. Lee SH. Intestinal permeability regulation by tight junction: implication on inflammatory bowel diseases. Intest Res (2015) 13:11-8. doi:10.5217/ ir.2015.13.1.11

24. Hartsock A, Nelson WJ. Adherens and tight junctions: structure, function and connections to the actin cytoskeleton. Biochim Biophys Acta (2008) 3:660-9. doi:10.1016/j.bbamem.2007.07.012

25. Van Itallie CM, Anderson JM. The role of claudins in determining paracellular charge selectivity. Proc Am Thorac Soc (2004) 1:38-41. doi:10.1513/ pats. 2306013

26. Günzel D, Yu AS. Claudins and the modulation of tight junction permeability. Physiol Rev (2013) 93:525-69. doi:10.1152/physrev.00019.2012

27. Rosenthal R, Milatz S, Krug SM, Oelrich B, Schulzke JD, Amasheh S, et al. Claudin-2, a component of the tight junction, forms a paracellular water channel. J Cell Sci (2010) 123:1913-21. doi:10.1242/jcs.060665

28. Travis S, Menzies I. Intestinal permeability: functional assessment and significance. Clin Sci (1992) 82:471-88. doi:10.1042/cs0820471

29. Ménard S, Cerf-Bensussan N, Heyman M. Multiple facets of intestinal permeability and epithelial handling of dietary antigens. Mucosal Immunol (2010) 3:247-59. doi:10.1038/mi.2010.5

30. Van Itallie CM, Jennifer Holmes J, Bridges A, Gookin JL, Coccaro MR, Proctor W, et al. The density of small tight junction pores varies among cell types and is increased by expression of claudin-2. J Cell Sci (2008) 121:298-305. doi:10.1242/jcs.021485

31. Suzuki H, Tani K, Tamura A, Tsukita S, Fujiyoshi Y. Model for the architecture of claudin-based paracellular ion channels through tight junctions. J Mol Biol (2015) 427:291-7. doi:10.1016/j.jmb.2014.10.020

32. Neutra MR, Mantis NJ, Kraehenbuhl JP. Collaboration of epithelial cells with organized mucosal lymphoid tissues. Nat Immunol (2001) 2:1004-9. doi:10.1038/ni1101-1004

33. Rescigno M, Rotta G, Valzasina B, Ricciardi-Castagnoli P. Dendritic cells shuttle microbes across gut epithelial monolayers. Immunobiology (2001) 204:572-81. doi:10.1078/0171-2985-00094

34. Niess JH, Brand S, Gu X, Jung S, McCormickm BA, Vyas JM, et al. CX3CR1mediated dendritic cell access to the intestinal lumen and bacterial clearance. Science (2005) 307:254-8. doi:10.1126/science.1102901

35. Chieppa M, Rescigno M, Huang AY, Germain RN. Dynamic imaging of dendritic cell extension into the small bowel lumen in response to epithelial cell TLR engagement. J Exp Med (2003) 203:2841-52. doi:10.1084/ jem.20061884

36. McDole JR, Wheeler LW, McDonald KG, Wang B, Konjufca V, Knoop KA, et al. Goblet cells deliver luminal antigen to CD103+ dendritic cells in the small intestine. Nature (2012) 483:345-9. doi:10.1038/nature10863

37. Miron N, Cristea V. Enterocytes: active cells in tolerance to food and microbial antigens in the gut. Clin Exp Immunol (2012) 167:405-12. doi:10.1111/j.1365-2249.2011.04523.x

38. Howe SE, Lickteig DJ, Plunkett KN, Ryerse JS, Konjufca V. The uptake of soluble and particulate antigens by epithelial cells in the mouse small intestine. PLoS One (2014) 9(1):e86656. doi:10.1371/journal.pone.0086656

39. Tuma PL, Hubbard AL. Transcytosis: crossing cellular barriers. Physiol Rev (2003) 83:871-932. doi:10.1152/physrev.00001.2003

40. Pabst O, Mowat AM. Oral tolerance to food protein. Mucosal Immunol (2012) 5:232-9. doi:10.1038/mi.2012.4

41. Dixon JB. Mechanisms of chylomicron uptake into lacteals. Ann N Y Acad Sci (2010) 1207(Suppl 1):E52-7. doi:10.1111/j.1749-6632.2010.05716.x

42. Heyman M, Ducroc R, Desjeux JF, Morgat JL. Horseradish peroxidase transport across adult rabbit jejunum in vitro. Am J Physiol (1982) 242:G558-64.

43. Raposo G, Stoorvogel WE. Extracellular vesicles: exosomes, microvesicles, and friends. J Cell Biol (2013) 200:373-83. doi:10.1083/jcb.201211138

44. Gutiérrez-Vázquez C, Villarroya-Beltri C, Mittelbrunn M, SánchezMadrid F. Transfer of extracellular vesicles during immune cell-cell interactions. Immunol Rev (2013) 251:125-42. doi:10.1111/imr.12013

45. Mallegol J, Van Niel G, Lebreton C, Lepelletier Y, Candalh C, Dugave C, et al. T84-intestinal epithelial exosomes bear MHC class II/peptide complexes potentiating antigen presentation by dendritic cells. Gastroenterology (2007) 132:1866-76. doi:10.1053/j.gastro.2007.02.043

46. Van Niel G, Raposo G, Candalh C, Boussac M, Hershberg R, CerfBensussan N, et al. Intestinal epithelial cells secrete exosome-like vesicles. Gastroenterology (2001) 121:337-49. doi:10.1053/gast.2001.26263 
47. Vojdani A. For the assessment of intestinal permeability, size matters. Altern Ther Health Med (2013) 19:12-24.

48. Mantis NJ, Rol N, Corthésy B. Secretory IgA's complex roles in immunity and mucosal homeostasis in the gut. Mucosal Immunol (2011) 4:603-11. doi:10.1038/mi.2011.41

49. Kadaoui KA, Corthésy B. Secretory IgA mediates bacterial translocation to dendritic cells in mouse Peyer's patches with restriction to mucosal compartment. J Immunol (2007) 179:7751-7. doi:10.4049/jimmunol.179.11.7751

50. Catassi C, Fasano A. Celiac disease. Curr Opin Gastroenterol (2008) 24:687-91. doi:10.1097/MOG.0b013e32830edc1e

51. Shan L, Qiao SW, Arentz-Hansen H, Molberg Ø, Gray GM, Sollid LM, et al. Identification and analysis of multivalent proteolytically resistant peptides from gluten: implications for celiac sprue. J Proteome Res (2005) 4:1732-41. doi:10.1021/pr050173t

52. Matysiak-Budnik T, Moura IC, Arcos-Fajardo M, Lebreton C, Ménard S, Candalh C, et al. Secretory IgA mediates retrotranscytosis of intact gliadin peptides via the transferrin receptor in celiac disease. J Exp Med (2008) 205:143-54. doi:10.1084/jem.20071204

53. Yu LC. Intestinal epithelial barrier dysfunction in food hypersensitivity. J Allergy (2012) 2012:596081. doi:10.1155/2012/596081

54. Yang PC, Berin MC, Yu LC, Perdue MH. Enhanced intestinal transepithelial antigen transport in allergic rats is mediated by $\operatorname{IgE}$ and CD23 (FcepsilonRII). J Clin Invest (2000) 106:879-86. doi:10.1172/JCI9258

55. Ulluwishewa D, Anderson RC, McNabb WC, Moughan PJ, Wells JM, Roy NC. Regulation of tight junction permeability by intestinal bacteria and dietary components. J Nutr (2011) 141:769-76. doi:10.3945/ jn. 110.135657

56. Shimizu M. Interaction between food substances and the intestinal epithelium. Biosci Biotechnol Biochem (2010) 74:232-41. doi:10.1271/bbb.90730

57. Scow JS, Tavakkolizadeh A, Zheng Y, Sarr MG. Acute "adaptation" by the small intestinal enterocyte: a post-transcriptional mechanism involving apical translocation of nutrient transporters. Surgery (2011) 149:601-5. doi:10.1016/j.surg.2011.02.001

58. Welsch CA, Lachance PA, Wasserman BP. Dietary phenolic compounds: inhibition of $\mathrm{Na}$--dependent $\mathrm{D}$-glucose uptake in rat intestinal brush border membrane vesicles. J Nutr (1989) 119:1698-704.

59. Shimizu M, Kobayashi Y, Suzuki M, Satsu H, Miyamoto Y. Regulation of intestinal glucose transport by tea catechins. Biofactors (2000) 13:61-5. doi:10.1002/biof.5520130111

60. Yoshikawa M, Murakami T, Kadoya M, Murakami N, Yamahara J, Matsuda H. Medicinal foodstuffs. IX. The inhibitors of glucose absorption from the leaves of Gymnema sylvestre R. BR. (Asclepiadaceae): structures of gymnemosides a and b. Chem Pharm Bull (Tokyo) (1997) 45:1671-6. doi:10.1248/cpb.45.2034

61. Fleet JC, Schoch RD. Molecular mechanisms for regulation of intestinal calcium absorption by vitamin D and other factors. Crit Rev Clin Lab Sci (2010) 47:181-95. doi:10.3109/10408363.2010.536429

62. Takano Y, Matsuura T, Yoshikawa Y, Satsu H, Sato R, Shimizu M. Modulation of the intestinal $\mathrm{Ca} 2^{+}$uptake by a cheese whey protein digest. Biosci Biotechnol Biochem (2007) 71:1487-93. doi:10.1271/bbb.60721

63. Wapnir RA, Teichberg S. Regulation mechanisms of intestinal secretion: implications in nutrient absorption. J Nutr Biochem (2002) 13:190-9. doi:10.1016/S0955-2863(02)00181-X

64. Sabbatini ME. Natriuretic peptides as regulatory mediators of secretory activity in the digestive system. Regul Pept (2009) 154:5-15. doi:10.1016/j. regpep.2009.02.009

65. Qiu W, Lee B, Lancaster M, Xu W, Leung S, Guggino SE. Cyclic nucleotide-gated cation channels mediate sodium and calcium influx in rat colon. Am J Physiol Cell Physiol (2000) 278:C336-43.

66. Cha B, Kim JH, Hut H, Hogema BM, Nadarja J, Zizak M, et al. cGMP inhibition of $\mathrm{Na}+/ \mathrm{H}+$ antiporter 3 (NHE3) requires PDZ domain adapter NHERF2, a broad specificity protein kinase G-anchoring protein. J Biol Chem (2005) 280:16642-50. doi:10.1074/jbc.M500505200

67. Zizak M, Lamprecht G, Steplock D, Tariq N, Shenolikar S, Donowitz M, et al. cAMP-induced phosphorylation and inhibition of $\mathrm{Na}(+) / \mathrm{H}(+)$ exchanger 3 (NHE3) are dependent on the presence but not the phosphorylation of NHE regulatory factor. J Biol Chem (1999) 274:24753-8. doi:10.1074/ jbc. 274.35 .24753
68. Arshad N, Visweswariah SS. Cyclic nucleotide signaling in intestinal epithelia: getting to the gut of the matter. Wiley Interdiscip Rev Syst Biol Med (2013) 5:409-24. doi:10.1002/wsbm.1223

69. Benson K, Cramer S, Galla HJ. Impedance-based cell monitoring: barrier properties and beyond. Fluids Barriers CNS (2013) 10:5. doi:10.1186/2045-8118-10-5

70. Peng X, Yan H, You Z, Wang P, Wang S. Effects of enteral supplementation with glutamine granules on intestinal mucosal barrier function in severe burned patients. Burns (2004) 30:135-9. doi:10.1016/j.burns.2003.09.032

71. Ding LA, Li JS. Effects of glutamine on intestinal permeability and bacterial translocation in TPN-rats with endotoxemia. World J Gastroenterol (2003) 9:1327-32. doi:10.3748/wjg.v9.i6.1327

72. Li N, DeMarco VG, West CM, Andrews EL. Glutamine supports recovery from loss of transepithelial resistance and increase of permeability induced by media change in Caco-2 cells. J Nutr Biochem (2003) 14:401-8. doi:10.1016/ S0955-2863(03)00071-8

73. Li N, Lewis P, Samuelson D, Liboni K, Neu J. Glutamine regulates Caco-2 cell tight junction proteins. Am J Physiol Gastrointest Liver Physiol (2004) 287:G726-33. doi:10.1152/ajpgi.00012.2004

74. Li N, Neu J. Glutamine deprivation alters intestinal tight junctions via a PI3-K/Akt mediated pathway in Caco-2 cells. J Nutr (2009) 139:710-4. doi:10.3945/jn.108.101485

75. Basuroy S, Sheth P, Mansbach CM, Rao RK. Acetaldehyde disrupts tight junctions and adherens junctions in human colonic mucosa: protection by EGF and L-glutamine. Am J Physiol Gastrointest Liver Physiol (2005) 289:G367-75. doi:10.1152/ajpgi.00464.2004

76. Watanabe J, Fukumoto K, Fukushi E, Sonoyama K, Kawabata J. Isolation of tryptophan as an inhibitor of ovalbumin permeation and analysis of its suppressive effect on oral sensitization. Biosci Biotechnol Biochem (2004) 68:59-65. doi:10.1271/bbb.68.59

77. Yasumatsu H, Tanabe S. The casein peptide Asn-Pro-Trp-Asp-Gln enforces the intestinal tight junction partly by increasing occludin expression in Caco-2 cells. Br J Nutr (2010) 104:951-6. doi:10.1017/S0007114510001698

78. Hashimoto K, Nakayama T, Shimizu M. Effects of beta-lactoglobulin on the tight-junctional stability of Caco-2-SF monolayer. Biosci Biotechnol Biochem (1998) 62:1819-21. doi:10.1271/bbb.62.1819

79. Kong J, Zhang Z, Musch MW, Ning G, Sun J, Hart J, et al. Novel role of the vitamin $D$ receptor in maintaining the integrity of the intestinal mucosal barrier. Am J Physiol Gastrointest Liver Physiol (2008) 294:G208-16. doi:10.1152/ ajpgi.00398.2007

80. Maciel AA, Oria RB, Braga-Neto MB, Braga AB, Carvalho EB, Lucena $\mathrm{HB}$, et al. Role of retinol in protecting epithelial cell damage induced by Clostridium difficile toxin A. Toxicon (2007) 50:1027-40. doi:10.1016/j. toxicon.2007.07.010

81. Suzuki T, Hara H. Quercetin enhances intestinal barrier function through the assembly of zonula occludens-2, occludin, and claudin- 1 and the expression of claudin-4 in Caco-2 cells. J Nutr (2009) 139:965-74. doi:10.3945/ jn.108.100867

82. Amasheh M, Schlichter S, Amasheh S, Mankertz J, Zeitz M, Fromm M, et al. Quercetin enhances epithelial barrier function and increases claudin-4 expression in Caco-2 cells. J Nutr (2008) 138:1067-73.

83. Suzuki T, Tanabe S, Hara H. Kaempferol enhances intestinal barrier function through the cytoskeletal association and expression of tight junction proteins in Caco-2 cells. J Nutr (2011) 141:87-94. doi:10.3945/jn.110.125633

84. Rao RK, Basuroy S, Rao VU, Karnaky KJ Jr, Gupta A. Tyrosine phosphorylation and dissociation of occludin-ZO-1 and E-cadherin-beta-catenin complexes from the cytoskeleton by oxidative stress. Biochem J (2002) 368:471-81. doi:10.1042/bj20011804

85. Atkinson KJ, Rao RK. Role of protein tyrosine phosphorylation in acetaldehyde-induced disruption of epithelial tight junctions. Am J Physiol Gastrointest Liver Physiol (2001) 280:G1280-8.

86. Hollon J, Puppa EL, Greenwald B, Goldberg E, Guerrerio A, Fasano A. Effect of gliadin on permeability of intestinal biopsy explants from celiac disease patients and patients with non-celiac gluten sensitivity. Nutrients (2015) 7:1565-76. doi:10.3390/nu7031565

87. Lammers KM, Lu R, Brownley J, Lu B, Gerard C, Thomas K, et al. Gliadin induces an increase in intestinal permeability and zonulin release by binding 
to the chemokine receptor CXCR3. Gastroenterology (2008) 135:194.e-204.e. doi:10.1053/j.gastro.2008.03.023

88. Fasano A. Physiological, pathological, and therapeutic implications of zonulin-mediated intestinal barrier modulation. Am J Pathol (2008) 173:1243-52. doi:10.2353/ajpath.2008.080192

89. Visser J, Rozinga J, Sapone A, Lammers K, Fasano A. Tight junctions, intestinal permeability, and autoimmunity celiac disease and type 1 diabetes paradigms. AnnNYAcadSci (2009) 1165:195-205.doi:10.1111/j.1749-6632.2009.04037.x

90. Lammers KM, Chieppa M, Liu L, Liu S, Omatsu T, JankaJunttila M, et al. Gliadin induces neutrophil migration via engagement of the formyl peptide receptor, FPR1. PLoS One (2015) 10(9):e0138338. doi:10.1371/journal. pone. 0138338

91. Usami M, Muraki K, Iwamoto M, Ohata A, Matsushita E, Miki A. Effect of eicosapentaenoic acid (EPA) on tight junction permeability in intestinal monolayer cells. Clin Nutr (2001) 20:351-9. doi:10.1054/clnu.2001.0430

92. Usami M, Komurasaki T, Hanada A, Ohata A, Matsushita E, Miki A. Effect of gamma-linolenic acid or docosahexaenoic acid on tight junction permeability in intestinal monolayer cells and their mechanism by protein kinase C activation and/or eicosanoid formation. Nutrition (2003) 19:150-6. doi:10.1016/S0899-9007(02)00927-9

93. Willemsen LE, Koetsier MA, Balvers M, Beermann C, Stahl B, van Tol EA. Polyunsaturated fatty acids support epithelial barrier integrity and reduce IL-4 mediated permeability in vitro. Eur J Nutr (2008) 47:183-91. doi:10.1007/s00394-008-0712-0

94. Anderberg EK, Lindmark T, Artursson P. Sodium caprate elicits dilatations in human intestinal tight junctions and enhances drug absorption by the paracellular route. Pharm Res (1993) 10:857-64. doi:10.102 3/A:1018909210879

95. Lindmark T, Nikkila T, Artursson P. Mechanisms of absorption enhancement by medium chain fatty acids in intestinal epithelial Caco-2 cell monolayers. $J$ Pharmacol Exp Ther (1995) 275:958-64.

96. Bordin M, D’Atri F, Guillemot L, Citi S. Histone deacetylase inhibitors up-regulate the expression of tight junction proteins. Mol Cancer Res (2004) 2:692-701.

97. Suzuki T, Yoshida S, Hara H. Physiological concentrations of short-chain fatty acids immediately suppress colonic epithelial permeability. Br J Nutr (2008) 100:297-305. doi:10.1017/S0007114508888733

98. Schipper NG, Olsson S, Hoogstraate JA, deBoer AG, Vårum KM, Artursson P. Chitosans as absorption enhancers for poorly absorbable drugs 2 : mechanism of absorption enhancement. Pharm Res (1997) 14:923-9. doi:10.102 3/A:1012160102740

99. Hashimoto K, Kawagishi H, Nakayama T, Shimizu M. Effect of capsianoside, a diterpene glycoside, on tight-junctional permeability. Biochim Biophys Acta (1997) 1323:281-90. doi:10.1016/S0005-2736(96)00196-4

100. Finamore A, Massimi M, Conti Devirgiliis L, Mengheri E. Zinc deficiency induces membrane barrier damage and increases neutrophil transmigration in Caco-2 cells. J Nutr (2008) 138:1664-70.

101. Ma TY, Nguyen D, Bui V, Nguyen H, Hoa N. Ethanol modulation of intestinal epithelial tight junction barrier. Am J Physiol (1999) 276:G965-74.

102. Ferrier L, Berard F, Debrauwer L, Chabo C, Langella P, Buéno L, et al. Impairment of the intestinal barrier by ethanol involves enteric microflora and mast cell activation in rodents. Am J Pathol (2006) 168:1148-54. doi:10.2353/ajpath.2006.050617

103. Rao RK. Acetaldehyde-induced increase in paracellular permeability in Caco-2 cell monolayer. Alcohol Clin Exp Res (1998) 22:1724-30. doi:10.111 1/j.1530-0277.1998.tb03972.x

104. Sheth P, Seth A, Atkinson KJ, Gheyi T, Kale G, Giorgianni F, et al. Acetaldehyde dissociates the PTP1B-E-cadherin-beta-catenin complex in Caco-2 cell monolayers by a phosphorylation-dependent mechanism. Biochem J (2007) 402:291-300. doi:10.1042/BJ20060665

105. Watson JL, Ansari S, Cameron H, Wang A, Akhtar M, McKay DM. Green tea polyphenol (-)-epigallocatechin gallate blocks epithelial barrier dysfunction provoked by IFN-gamma but not by IL-4. Am J Physiol Gastrointest Liver Physiol (2004) 287:G954-61. doi:10.1152/ajpgi.00302.2003

106. Schmitz H, Fromm M, Bentzel CJ, Scholz P, Detjen K, Mankertz J, et al. Tumor necrosis factor-alpha (TNFalpha) regulates the epithelial barrier in the human intestinal cell line HT-29/B6. J Cell Sci (1999) 112:137-46.
107. Ye D, Ma I, Ma TY. Molecular mechanism of tumor necrosis factor-alpha modulation of intestinal epithelial tight junction barrier. Am J Physiol Gastrointest Liver Physiol (2006) 290:G496-504. doi:10.1152/ajpgi.00318.2005

108. Al-Sadi RM, Ma TY. IL-1beta causes an increase in intestinal epithelial tight junction permeability. J Immunol (2007) 178:4641-9. doi:10.4049/ jimmunol.178.7.4641

109. Xu C, Li CY, Kong AN. Induction of phase I, II and III drug metabolism/ transport by xenobiotics. Arch Pharm Res (2005) 28:249-68. doi:10.1007/ BF02977789

110. Jeong EJ, Liu X, Jia X, Chen J, Hu M. Coupling of conjugating enzymes and efflux transporters: impact on bioavailability and drug interactions. Curr Drug Metab (2005) 6:455-68. doi:10.2174/138920005774330657

111. Satsu H, Hiura Y, Mochizuki K, Hamada M, Shimizu M. Activation of pregnane $\mathrm{X}$ receptor and induction of MDR1 by dietary phytochemicals. J Agric Food Chem (2008) 56:5366-73. doi:10.1021/jf073350e

112. Carding S, Verbeke K, Vipond DT, Corfe BM, Owen LJ. Dysbiosis of the gut microbiota in disease. Microb Ecol Health Dis (2015) 26:26191. doi:10.3402/ mehd.v26.26191

113. Tremaroli V, Bäckhed F. Functional interactions between the gut microbiota and host metabolism. Nature (2012) 489:242-9. doi:10.1038/ nature11552

114. Leblanc JG, Milani C, de Giori GS, Sesma F, van Sinderen D, Ventura M. Bacteria as vitamin suppliers to their host: a gut microbiota perspective. Curr Opin Biotechnol (2013) 24(2):160-8. doi:10.1016/j.copbio.2012.08.005

115. Burkholder PR, McVeigh I. Synthesis of vitamins by intestinal bacteria. Proc Natl Acad Sci U S A (1942) 28:285-9. doi:10.1073/pnas.28.7.285

116. Tazoe H, Otomo Y, Kaji I, Karaki SI, Kuwahara A. Roles of short-chain fatty acids receptors, GPR41 and GPR43 on colonic functions. J Physiol Pharmacol (2008) 59:251-62.

117. Selma MV, Espin JC, Tomas-Barberan FA. Interaction between phenolics and gut microbiota: role in human health. J Agric Food Chem (2009) 57:6485-501. doi:10.1021/jf902107d

118. Queipo-Ortuno MI, Boto-Ordonez M, Murri M, Gomez-Zumaquero JM, Clemente-Postigo M, Estruch R, et al. Influence of red wine polyphenols and ethanol on the gut microbiota ecology and biochemical biomarkers. Am J Clin Nutr (2012) 95:1323-34. doi:10.3945/ajen.111.027847

119. Cavalcanti E, Vadrucci E, Delvecchio FR, Addabbo F, Bettini S, Liou R, et al. Administration of reconstituted polyphenol oil bodies efficiently suppresses dendritic cell inflammatory pathways and acute intestinal inflammation. PLoS One (2014) 9:e88898. doi:10.1371/journal.pone.0088898

120. Delvecchio FR, Vadrucci E, Cavalcanti E, De Santis S, Kunde D, Vacca M, et al. Polyphenol administration impairs T-cell proliferation by imprinting a distinct dendritic cell maturational profile. Eur J Immunol (2015) 45:2638-49. doi:10.1002/eji.201545679

121. Hylemon PB, Zhou H, Pandak WM, Ren S, Gil G, Dent P. Bile acids as regulatory molecules. J Lipid Res (2009) 50:1509-20. doi:10.1194/jlr. R900007-JLR200

122. Rajilić-Stojanović M, Jonkers DM, Salonen A, Hanevik K, Raes J, Jalanka J, et al. Intestinal microbiota and diet in IBS: causes, consequences, or epiphenomena? Am J Gastroenterol (2015) 110:278-87. doi:10.1038/ajg.2014.427

123. Stoidis CN, Misiakos EP, Patapis P, Fotiadis CI, Spyropoulos BG. Potential benefits of pro- and prebiotics on intestinal mucosal immunity and intestinal barrier in short bowel syndrome. Nutr Res Rev (2011) 24:21-30. doi:10.1017/ S0954422410000260

124. Guzman JR, Conlin VS, Jobin C. Diet, microbiome, and the intestinal epithelium: an essential triumvirate? Biomed Res Int (2013) 2013:425146. doi:10.1155/2013/425146

125. Wegener J, Abrams D, Willenbrink W, Galla HJ, Janshoff A. Automated multi-well device to measure transepithelial electrical resistances under physiological conditions. Biotechniques (2004) 590(592-4):596-7. doi: $10.2144 / 3704 \mathrm{~A} 0590$

126. Shen L, Weber CR, Raleigh DR, Yu D, Turner JR. Tight junction pore and leak pathways: a dynamic duo. Annu Rev Physiol (2011) 73:283-309. doi:10.1146/ annurev-physiol-012110-142150

127. Bischoff SC, Barbara G, Buurman W, Ockhuizen T, Schulzke JD, Serino $\mathrm{M}$, et al. Intestinal permeability - a new target for disease prevention and therapy. BMC Gastroenterol (2014) 14:189. doi:10.1186/s12876-014-0189-7 
128. Clarke LL. A guide to Ussing chamber studies of mouse intestine. Am J Physiol Gastrointest Liver Physiol (2009) 296:G1151-66. doi:10.1152/ ajpgi.90649.2008

129. Arrieta MC, Bistritz L, Meddings JB. Alterations in intestinal permeability. Gut (2006) 55:1512-20. doi:10.1136/gut.2005.085373

130. Bijlsma PB, Peeters RA, Groot JA, Dekker PR, Taminiau JA, Van Der Meer R. Differential in vivo and in vitro intestinal permeability to lactulose and mannitol in animals and humans: a hypothesis. Gastroenterology (1995) 108:687-96. doi:10.1016/0016-5085(95)90440-9

131. Gotteland M, Isolauri E, Heyman M, Tome D, Desjeux JF. Antigen absorption in bacterial diarrhea: in vivo intestinal transport of beta-lactoglobulin in rabbits infected with the entero-adherent Escherichia coli strain RDEC-1. Pediatr Res (1989) 26:237-40. doi:10.1203/00006450-198909000-00016

132. Öhman L, Törnblom H, Simrén M. Crosstalk at the mucosal border: importance of the gut microenvironment in IBS. Nat Rev Gastroenterol Hepatol (2015) 12:36-49. doi:10.1038/nrgastro.2014.200

133. Mowat AM. Anatomical basis of tolerance and immunity to intestinal antigens. Nat Rev Immunol (2003) 3:331-41. doi:10.1038/nri1057

134. Rescigno M, Chieppa M. Gut-level decisions in peace and war. Nat Med (2005) 11:254-5. doi:10.1038/nm0305-254

135. Mowat AM, Agace WW. Regional specialization within the intestinal immune system. Nat Rev Immunol (2014) 14:667-85. doi:10.1038/nri3738

136. Capaldo CT, Nusrat A. Cytokine regulation of tight junctions. Biochim Biophys Acta (2009) 1788:864-71. doi:10.1016/j.bbamem.2008.08.027

137. McKay DM, Baird AW. Cytokine regulation of epithelial permeability and ion transport. Gut (1999) 44:283-9. doi:10.1136/gut.44.2.283

138. Amasheh M, Fromm A, Krug SM, Amasheh S, Andres S, Zeitz M, et al. TNFalpha-induced and berberine-antagonized tight junction barrier impairment via tyrosine kinase, Akt and NFkappaB signaling. J Cell Sci (2010) 123:4145-55. doi:10.1242/jcs.070896

139. Satsu H, Shimizu M. Food factors that regulate intestinal inflammation: evaluation of the factors by using a coculture system. In: Iijima S, Nishijima K, editors. Animal Cell Technology: Basic \& Applied Aspect. Dordrecht, The Netherlands: Springer (2006). p. 29-37.

140. Zhao Z, Satsu H, Fujisawa M, Hori M, Ishimoto Y, Totsuka M, et al. Attenuation by dietary taurine of dextran sulfate sodium-induced colitis in mice and of THP-1-induced damage to intestinal Caco-2 cell monolayers. Amino Acids (2008) 35:217-24. doi:10.1007/s00726-007-0562-8

141. Shimizu M, Satsu H. Physiological significance of taurine and the taurine transporter in intestinal epithelial cells. Amino Acids (2000) 19:605-14. doi:10.1007/s007260070010

142. Mochizuki T, Satsu H, Shimizu M. Tumor necrosis factor alpha stimulates taurine uptake and transporter gene expression in human intestinal Caco-2 cells. FEBS Lett (2002) 517:92-6. doi:10.1016/S0014-5793(02)02584-X

143. Mochizuki T, Satsu H, Shimizu M. Signaling pathways involved in tumor necrosis factor alpha-induced upregulation of the taurine transporter in Caco-2 cells. FEBS Lett (2005) 579:3069-74. doi:10.1016/j.febslet.2005.04.063

144. Magrone T, de Heredia F, Jirillo E, Morabito G, Marcos A, Serafini M. Functional foods and nutraceuticals as therapeutic tools for the treatment of diet-related diseases. Can J Physiol Pharmacol (2013) 91(6):387-96. doi:10.1139/cjpp-2012-0307

145. Magrone T, Jirillo E. The interplay between the gut immune system and microbiota in health and disease: nutraceutical intervention for restoring intestinal homeostasis. Curr Pharm Des (2013) 19:1329-42. doi:10.2174/138161213804805793

146. Magrone T, Jirillo E. The interaction between gut microbiota and age-related changes in immune function and inflammation. Immun Ageing (2013) 10:31. doi:10.1186/1742-4933-10-31

147. Verna EC. Use of probiotics in gastrointestinal disorders: what to recommend? Therap Adv Gastroenterol (2010) 3:307-19. doi:10.1177/1756283X10373814

148. Ringel Y, Quigley EMM, Lin HC. Using probiotics in gastrointestinal disorders. Am J Gastroenterol Suppl (2012) 1:34-40. doi:10.1038/ajgsup.2012.7

149. Matsuzaki T, Chin J. Modulating immune responses with probiotic bacteria. Immunol Cell Biol (2000) 78:67-73. doi:10.1046/j.1440-1711.2000.00887.x

150. de Vrese M. Effects of probiotic bacteria on gastrointestinal symptoms, Helicobacter pylori activity and antibiotics-induced diarrhea. Gastroenterology (2003) 124:A560. doi:10.1016/S0016-5085(03)82836-6
151. Pochard P, Gosset P, Grangette C, Andre C, Tonnel AB, Pestel J, et al. Lactic acid bacteria inhibit TH2 cytokine production by mononuclear cells from allergic patients. J Allergy Clin Immunol (2002) 110:617-23. doi:10.1067/ mai.2002.128528

152. Nagao F, Nakayama M, Muto T, Okumura K. Effects of a fermented milk drink containing Lactobacillus casei strain Shirota on the immune system in healthy human subjects. Biosci Biotechnol Biochem (2000) 64:2706-8. doi:10.1271/bbb.64.2706

153. de Roos NM, Katan MB. Effects of probiotic bacteria on diarrhea, lipid metabolism, and carcinogenesis: a review of papers published between 1988 and 1998. Am J Clin Nutr (2000) 71:405-11.

154. Bowen JM, Stringer AM, Gibson RJ, Yeoh AS, Hannam S, Keefe DM. VSL\#3 probiotic treatment reduces chemotherapy-induced diarrhea and weight loss. Cancer Biol Ther (2007) 6:1449-54. doi:10.4161/cbt.6.9.4622

155. Mach T. Clinical usefulness of probiotics in inflammatory bowel diseases. $J$ Physiol Pharmacol (2006) 57(Suppl 9):23-33.

156. Chen YP, Hsiao PJ, Hong WS, Dai TY, Chen MJ. Lactobacillus kefiranofaciens M1 isolated from milk kefir grains ameliorates experimental colitis in vitro and in vivo. J Dairy Sci (2012) 95:63-74. doi:10.3168/jds.2011-4696

157. Apostolou E, Kirjavainen PV, Saxelin M, Rautelin H, Valtonen V, Salminen SJ, et al. Good adhesion properties of probiotics: a potential risk for bacteremia? FEMS Immunol Med Microbiol (2001) 31:35-9. doi:10.1111/j.1574695X.2001.tb01583.x

158. Yan F, Cao H, Cover TL, Washington MK, Shi Y, Liu L, et al. Colon-specific delivery of a probiotic-derived soluble protein ameliorates intestinal inflammation in mice through an EGFR-dependent mechanism. J Clin Invest (2011) 121:2242-53. doi:10.1172/JCI44031

159. de Vrese M, Schrezenmeir J. Probiotics, prebiotics, and synbiotics. Adv Biochem Eng Biotechnol (2008) 111:1-66. doi:10.1007/10_2008_097

160. Veerappan GR, Betteridge J, Young PE. Probiotics for the treatment of inflammatory bowel disease. Curr Gastroenterol Rep (2012) 14:324-33. doi:10.1007/s11894-012-0265-5

161. Bouhnik Y, Raskine L, Simoneau G, Vicaut E, Neut C, Flourié B, et al. The capacity of nondigestible carbohydrates to stimulate fecal bifidobacteria in healthy humans: a double-blind, randomized, placebo-controlled, parallel-group, dose-response relation study. Am J Clin Nutr (2004) 80:1658-64.

162. Gibson GR, Probert HM, Loo JV, Rastall RA, Roberfroid MB. Dietary modulation of the human colonic microbiota: updating the concept of prebiotics. Nutr Res Rev (2004) 17:259-75. doi:10.1079/NRR200479

163. Langlands SJ, Hopkins MJ, Coleman N, Cummings JH. Prebiotic carbohydrates modify the mucosa associated microflora of the human large bowel. Gut (2004) 53:1610-6. doi:10.1136/gut.2003.037580

164. Winkler J, Butler R, Symonds E. Fructo-oligosaccharide reduces inflammation in a dextran sodium sulphate mouse model of colitis. Dig Dis Sci (2007) 52:52-8. doi:10.1007/s10620-006-9224-z

165. Camuesco D, Peran L, Comalada M, Nieto A, Di Stasi LC, RodriguezCabezas ME, et al. Preventative effects of lactulose in the trinitrobenzenesulphonic acid model of rat colitis. Inflamm Bowel Dis (2005) 11:265-71. doi:10.1097/01.MIB.0000160808.30988.d9

166. Scaldaferri F, Gerardi V, Lopetuso LR, Del Zompo F, Mangiola F, Boškoski I, et al. Gut microbial flora, prebiotics, and probiotics in IBD: their current usage and utility. Biomed Res Int (2013) 2013:435268. doi:10.1155/2013/435268

167. Casellas F, Borruel N, Torrejón A, Varela E, Antolin M, Guarner F, et al. Oral oligofructose-enriched inulin supplementation in acute ulcerative colitis is well tolerated and associated with lowered faecal calprotectin. Aliment Pharmacol Ther (2007) 25:1061-7. doi:10.1111/j.1365-2036.2007.03288.x

168. Colman RJ, Rubin DT. Fecal microbiota transplantation as therapy for inflammatory bowel disease: a systematic review and meta-analysis. J Crohns Colitis (2012) 8:1569-81. doi:10.1016/j.crohns.2014.08.006

169. Chey WD, Kurlander J, Eswaran S. Irritable bowel syndrome: a clinical review. JAMA (2015) 313:949-58. doi:10.1001/jama.2015.0954

170. van Nood E, Vrieze A, Nieuwdorp M, Fuentes S, Zoetendal EG, de Vos WM, et al. Duodenal infusion of donor feces for recurrent Clostridium difficile. $N$ Engl J Med (2013) 368:407-15. doi:10.1056/NEJMoa1205037

171. Youngster I, Russell GH, Pindar C, Ziv-Baran T, Sauk J, Hohmann EL. Oral, capsulized, frozen fecal microbiota transplantation for relapsing Clostridium difficile infection. JAMA (2014) 312:1772-8. doi:10.1001/jama.2014.13875 
172. Dorsey KA, Moritz ED, Steele WR, Eder AF, Stramer SL. A comparison of human immunodeficiency virus, hepatitis $C$ virus, hepatitis B virus, and human T-lymphotropic virus marker rates for directed versus volunteer blood donations to the American Red Cross during 2005 to 2010. Transfusion (2013) 53:1250-6. doi:10.1111/j.1537-2995.2012.03904.x

173. Ridaura VK, Faith JJ, Rey FE, Cheng J, Duncan AE, Kau AL, et al. Gut microbiota from twins discordant for obesity modulate metabolism in mice. Science (2013) 341:1241214. doi:10.1126/science.1241214

174. Fonseca DM, Hand TW, Han SJ, Gerner MY, Glatman Zaretsky A, Byrd AL, et al. Microbiota-dependent sequelae of acute infection compromise tissue-specific immunity. Cell (2015) 163:354-66. doi:10.1016/j.cell.2015.08.030
Conflict of Interest Statement: The authors declare that the research was conducted in the absence of any commercial or financial relationships that could be construed as a potential conflict of interest.

Copyright $\odot 2015$ De Santis, Cavalcanti, Mastronardi, Jirillo and Chieppa. This is an open-access article distributed under the terms of the Creative Commons Attribution License (CC BY). The use, distribution or reproduction in other forums is permitted, provided the original author(s) or licensor are credited and that the original publication in this journal is cited, in accordance with accepted academic practice. No use, distribution or reproduction is permitted which does not comply with these terms. 